\title{
Difficulty in thoracic catheter insertion in a very obese patient
}

\author{
Yuika SASATANI ${ }^{1}$ (ID) \\ Kesato IGUCHI ${ }^{2}$ (ID) \\ Hiroaki SATOH ${ }^{1}$ (ID)
}

Cite this article as: Sasatani $Y$, Iguchi $K$, Satoh $H$. Difficulty in thoracic catheter insertion in a very obese patient. Tuberk Toraks 2021;69(4):567-568.

\section{Address for Correspondence (Yazışma Adresi)}

\section{Dr. Hiroaki SATOH}

Division of Respiratory Medicine,

Mito Medical Center, University of Tsukuba,

Miya-machi 3-2-7,

Ibaraki, 310-0015, MITO - JAPAN

e-mail: hirosato@md.tsukuba.ac.jp

CCopyright 2021 by Tuberculosis and Thorax.

Available on-line at www.tuberktoraks.org.com
${ }^{1}$ Division of Respiratory Medicine, Mito Medical Center, University of Tsukuba, Mito, Japan

${ }^{1}$ Tsukuba Üniversitesi Mito Tıp Merkezi, Solunum Tıbbı Bölümü, Mito, Japonya

2 Division of Thoracic Surgery, University of Tsukuba, Mito Medical Center, Mito, Japan

${ }^{2}$ Tsukuba Üniversitesi, Mito Tıp Merkezi, Göğ̈̈s Cerrahisi Anabilim Dalı, Mito, Japan

To the Editor,

A 61-year-old man presented with sudden onset of dyspnea. The patient had never smoked, but was diagnosed with rheumatoid arthritis and associated interstitial lung disease 6 years ago. He was $160 \mathrm{~cm}$ tall, weighed $97 \mathrm{~kg}$ (body mass index: $37.9 \mathrm{~kg} / \mathrm{m}^{2}$ ). On admission, physical examination revealed diminished breath sounds on right side. Initial chest CT demonstrated pneumothorax on the right side (Figure 1). As this was his first time episode of pneumothorax, deaeration was performed with a chest tube. Ultrasonography was used to determine the chest tube insertion site, but it was not easy to distinguish between the intercostal space and the ribs. The penetration distance from the skin to the thoracic cavity was long, and it took effort to advance the tip. Due to resistance from adipose tissue, it was difficult to advance the tube from the skin to the intercostal space, even though the inner indwelling needle was not removed in the process of performing this procedure. A chest radiograph taken at the end of the procedure showed that the chest tube did not reach the intercostal space in a straight line and was bent. Sufficient fixation was performed after tube insertion, but subcutaneous emphysema developed. Despite these difficulties, the patient's pneumothorax could be treated.

In the treatment of pneumothorax, deaeration with a chest tube is usually the treatment of choice. Unless there is pleural adhesion 


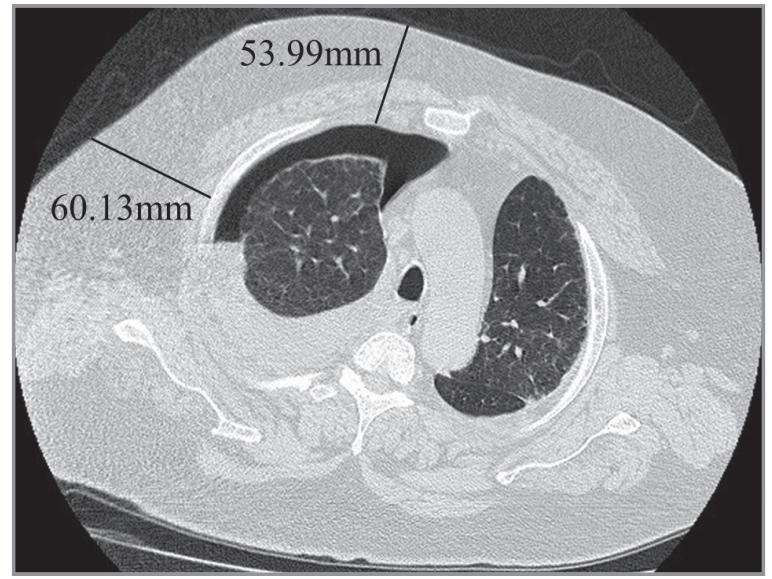

Figure 1. Chest CT scan taken at admission showed the anterior approach (from the surface of the anterior chest wall to the pleura) and lateral approach (from the surface of the lateral chest wall to the pleura) were $53.99 \mathrm{~cm}$ and $60.13 \mathrm{~cm}$, respectively.

and a special puncture site must be selected, the anterior or lateral part of the chest is the tube insertion site. When the thoracic muscles such as pectoralis major are developed and thickened, they are not suitable as insertion sites, so other puncture sites must be searched for. Spontaneous pneumothorax is mostly common in young, tall and lean men, so fat thickness is less of a consideration when chest tube insertion. However, pneumothorax can occur in patients who are centrally obese after receiving corticosteroids for some underlying diseases, such as obese patients with lung fibrosis who have been treated with corticosteroid for a long-term period. Difficulty in chest tube insertion in a very obese patients was reported previously $(1,2)$. In a patient reported by Ledochowski et al, the anterior approach (from the surface of the anterior chest wall to the pleura) and lateral approach (from the surface of the lateral chest wall to the pleura) were $26.42 \mathrm{~mm}$ and $51.37 \mathrm{~mm}$, respectively (1). In our patient, they were $53.99 \mathrm{~cm}$ and $60.13 \mathrm{~cm}$, respectively. Both approaches resulted in thicker in our patient than those in their patient. In these very obese patients, insertion of the thoracic catheter was very difficult. The difficulties involved in inserting and managing chest tube in our patient were as follows: the position of the ribs was not clear from the body surface. Even if the insertion site was determined using ultrasonography, there was a possibility that the site would shift due to the thick adipose tissue. As the penetration length of adipose tissue was long, the impression of reaching the pleura was not clear. It was not easy to insert the tip of the tube into the intercostal space. The tip of the tube did not deviate outside the thoracic cavity. However, subcutaneous emphysema occurred despite sufficient suturing of the puncture site. As reported in previous reports $(1,2)$, chest tube insertion in very obese patients is very difficult. Special attention should be paid to complications. Not done in this patient, for such operations, fluoroscopy and CT guide operations might be useful.

\section{REFERENCES}

1. Ledochowski S, Axiotis G, Wallet F, Friggeri A. Difficult needle decompression of bilateral tension pneumothoraces in an obese female patient. Intensive Care Med 2014; 40: $1749-50$.

2. Hatzigeorgiadis A, Boulas KA, Barettas N, Blouhos $K$. Bilateral primary spontaneous pneumothorax in an otherwise-healthy overweight young man. I Surg Case Rep 2014; 2014(8): rju076. 